\title{
Education and Curriculum Reform: The Impact They Have On Learning
}

\author{
Sharon Campbell-Phillips \\ Department of Education, University of the People, Pasadena, CA, USA \\ beautifulblushes@yahoo.com
}

\section{Abstract}

Globally, there has been a breakdown in the area of science education; therefore there is a great need for curriculum reform so that the vision and mission will be clearly stated and that the stakeholders will be fair when redesigning the curriculum so that it satisfies the needs of students. There have been recommendations for education programs emphasized issues, such as updated scientific and technologic knowledge, application of contemporary learning theory and teaching strategies" (Bybee \& McInerne, 1995). Also, there is a consensus amongst science teachers that students' study too many areas, without enough depth in each, therefore, a reform of the curriculum is of great need. Rodger W. Bybee of The National Academy of Science also reveals that the level of support for curriculum reform is unprecedented in the history of American education. Additionally, the curricula in middle schools contain too many disconnected themes. In addition, each topic is given equal priority which discourages the in-depth study of foundational topics. It is therefore recommended a revised curriculum that emphasizes a more practical set of foundational themes and concepts are needed in the study of science. For this study, the researcher used a combination of methods to gather data that was then analyzed. Questionnaires, surveys and observation were the channels to acquire information. The purpose of the study is to examine if education and curriculum reform can impact the way we learn, and how. The analyzed data will be used for further research as well as to influence curriculum reform in educational systems.

\section{Keywords}

curriculum; reform; education; school;

science

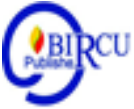

\section{Introduction}

Education plays a critical role in our lives and it is a bit blurry when to imagine what type of society we would have without education, and how we will function as individuals. Attending school and acquiring education is very critical to our development and it plays a major role in our life's journey. Education is the foundation of a successful career, financial freedom, the ability to think and reason critically and to make informed decisions. Without education we will be limited to perform tasks and we will be ignorant to the things that are happening in and around our surrounding, and according to Martin Luther King, a people without knowledge is like a tree without roots. For education to be of great value, curriculums should be implemented.

Curriculums are learning guides that are governed by a school board that is designed to address students' educational needs, facilitate learners while establishing relationships between teachers and students. They state the learning objectives, the grade letter and 
percentages, and the topics that are to be taught and the specific order. It also lists the content, materials, resources and the process for evaluating the set objectives.

Education and curriculums are connected and share a relationship in which both of them are enhanced. Education is highly recognized when its foundation is that of an effective curriculum. It is very important as students pay close attention to such especially when comparing and selecting schools in which to attend. Curriculums can enhance education, boost the reputation of schools and attract learners. However, within the curriculum, there are various pros and cons which should be considered.

The pros include the guidelines about what is to be taught, it teaches to the test and is easy to assess, it is research based, it coincides with political agendas and it provides educational opportunities for both teachers and students. The cons include the lack of interaction between teachers and students; place too much emphasis on observable behaviours, lack problem-solving ability and critical thinking, place more focus on societal needs instead of individual needs, standards and principles are not set by educators.

According to Bobbit (1876), curriculum is viewed as a science that emphasizes the needs of the students. Therefore, lessons are to be planned and organized depending on the needs of the students and these needs must be addressed by the teachers to prepare them for adult life, Franklin Bobbit (1876-1956). The purpose of curriculum is child development, growth, and social relationship. He also emphasized on group interaction, and the project method in which the teacher and students plan together. Thus, it is called as the childcentered curriculum, William Kilpatrick (1871-1965). Curriculum is very important and brings about order in the classroom and it helps students to be more organized when engaging in their school work and related activities. Thus, it is critical when designing curriculums and all the necessary factors should be considered.

\section{Research Method}

As a curriculum developer, for English in Speyside High school, the researcher begun by examining the three key points which are:

- The type of learner - examined the types of learner; their culture and their beliefs.

- The subject matter -carefully examined the subject; both the content and the knowledge.

- The societal force -examined the forces of society that influences the curriculum directly and indirectly. Questionnaires and surveys were given to teachers and policy makers to gather unbiased information about their views towards the subject. Observers were randomly chosen to visit various classrooms and observe both teachers and students. The information was analyzed and shown by various charts and graphs. Education is critical to our development; therefore, it is very important that curriculums are designed to give optimum results. 


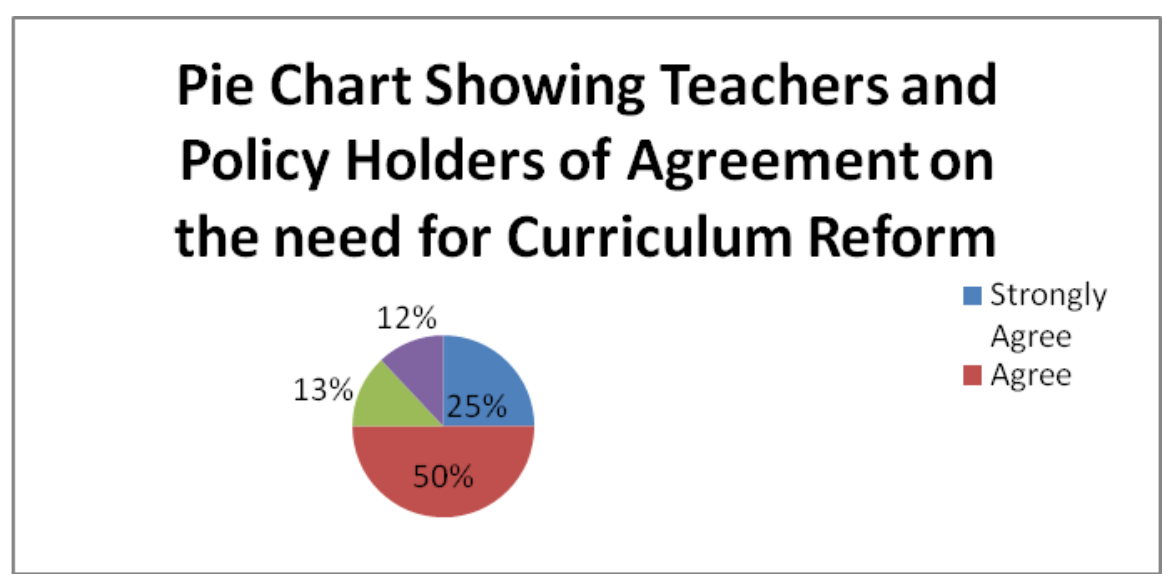

Figure 1

\section{Importance of Curriculum Reform for Optimum Success in Students}

Percentage

Distribution

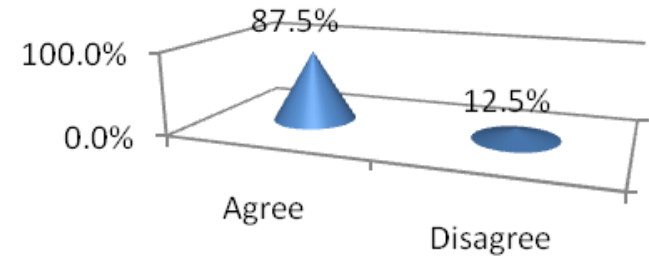

Categories of Agreement

Figure 2

Pie Chart Showing Percentage of

Persons Agreeing to Curriculum

Reform

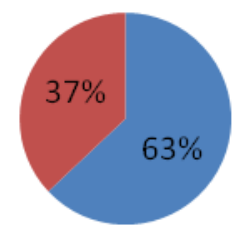

Figure 3 
Table showing the results of persons' decision that a reform in curriculum will be beneficial

\begin{tabular}{|l|l|l|l|l|}
\hline Strongly Agree & Agree & Undecided & Disagree & $\begin{array}{l}\text { Strongly } \\
\text { Disagree } \\
12.5 \%\end{array}$ \\
& $\mathbf{5 0 \%}$ & $\mathbf{3 7 . 5 \%}$ & $\mathbf{0 \%}$ & $\mathbf{0 \%}$ \\
\hline
\end{tabular}

Figure 4

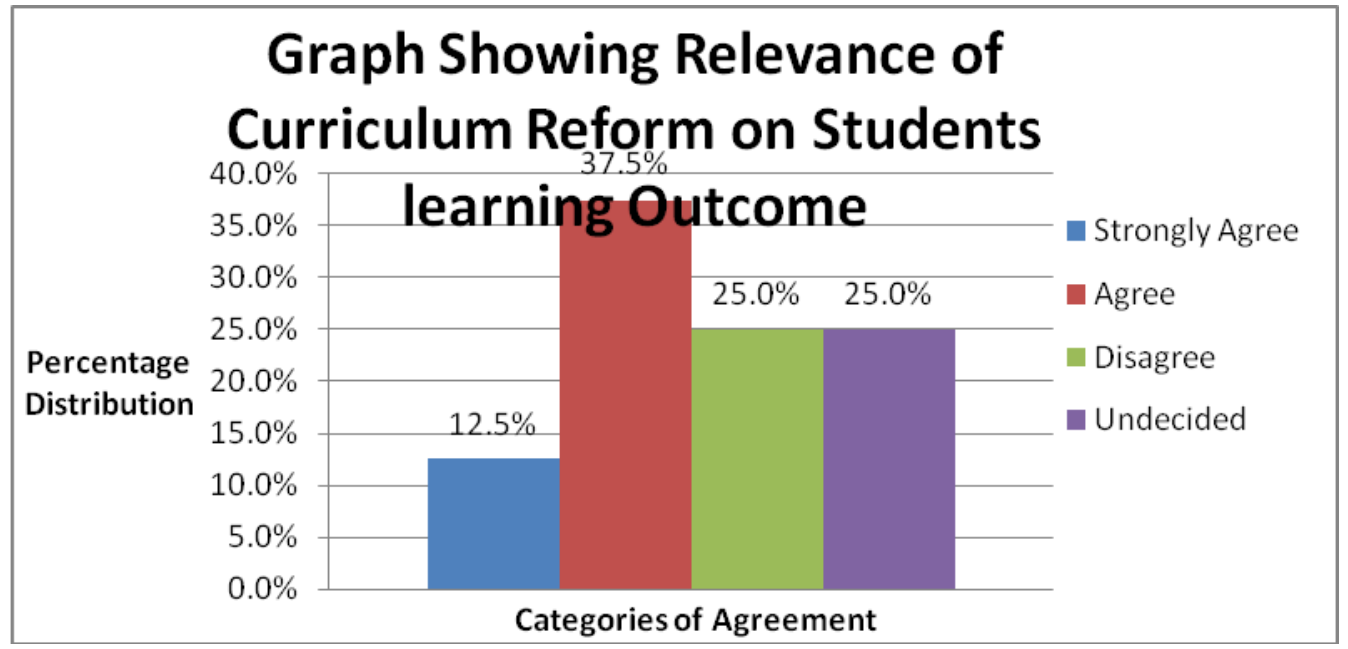

Figure 5

Part 1

Mind map

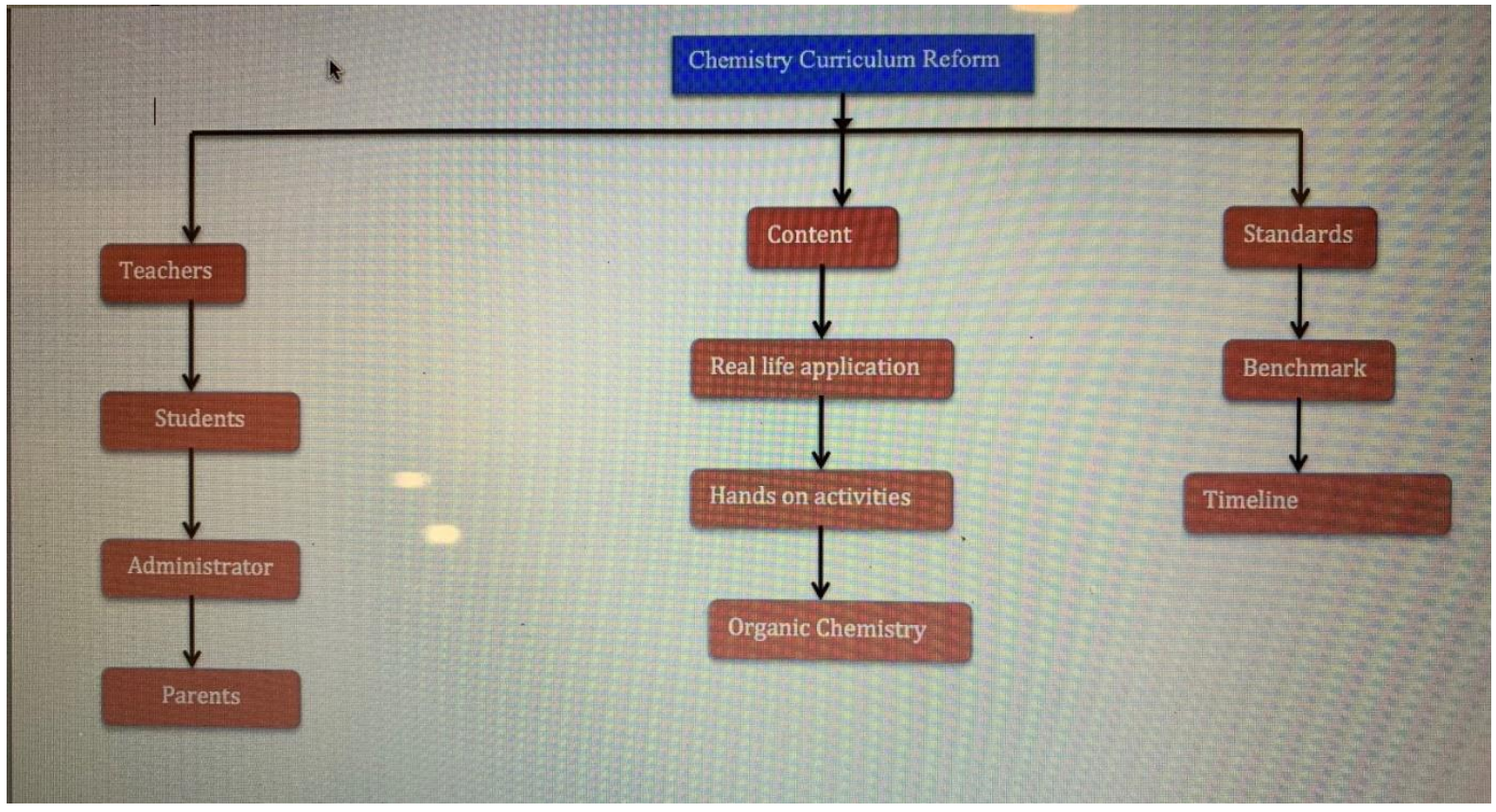

\section{Curriculum reform}

The process of curriculum reform could be a two or three (2 to 3 ) year's long plan. Stage 1: Survey (6 months) 
At this phase It is recommended that researchers gather information about the curriculum from different stakeholder regarding the curriculum. Different surveys for teachers, students, administrator and parents.

Stage 2: Analysis (Next three months)

At this stage share the information gathered and understands perspectives from different stakeholders. This would help to address the burning issues of curriculum in our reformation process.

Stage 3: Develop action plan (One year)

With frequent meeting the curriculum reformation committee can develop an action plan.

Stage 4: Implementation (One year)

In year 3, new curriculum can be implemented and followed by review and reflection at the end of the third year.

The established committee needs to meet main at following phases:

- Before survey (once)

- After survey to share the survey result (once)

- Curriculum reformation recommendation (Two times)

- Plan of action (2 times)

- Review the action plan once)

A curriculum reform should include a parent, a freshly graduate, teachers, curriculum director, school principal and two or three (2-3) subject teachers, one science teacher and 2 teachers from other subject area.

Research

Project 2061 is a long-term initiative of the American Association for the Advancement of Science (AAAS) to help all Americans become literate in science, mathematics, and technology.

"Project 2061 provides a coherent set of K-12 learning goals that serve as a foundation for state and national science education frameworks and standards, including the Next Generation Science Standards.”

Curriculum reformation

- Vertical alignment

- NGSS standards

- Differentiated activities

- Real life application

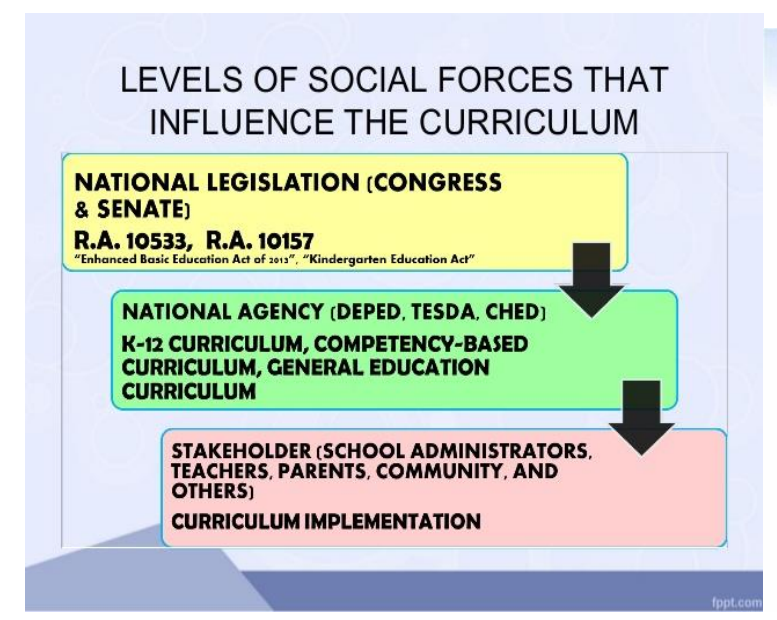

\section{SOCIETY AND CURRICULUM}

Schools are part and parcel of a society and exist for the society. Society influences schools through the curriculum. Schools, through their teaching of the
shape and mould society and society in turn can impact the curricul un

There is rarely a curriculum that is developed without reflecting the society. With advancements in information and communication technology, people are talking and sharing views across the globe.

Education systems are closely tied to the institutional network of society. Thus, to understand what is taught, how it is taught and why it is taught, we need to look at the (a) following

- To what extent should curriculum consider the world outside of school? - How do changes in society affect curriculum?

Knowing the social foundations of curriculum is crucial in making decisions about wh should be included in the curriculum and eventually what happens in the classeroor Schools exist within the context of society and influence culture which in turn shapes the curriculum. A curriculum should address the wants and needs of learners by responening 


\section{Observation}

As a result of the era of science education and its history, it is of great importance that leading-edge textbooks and curricula be developed. When starting a curriculum reform project, four key areas should be look at are:

- Standards- according to research, students are studying too many areas that are not of great quality; too little knowledge and information.

- Elementary education- there is an essential need for the study of science from the early childhood level. One way to reform various educations is by engaging young children because they are usually very responsive.

- Curriculum- The classroom need more problem-solving and demonstrative skills. Base on the curriculum design, students may/may not have a need to be able to be successful students.

- Teachers- teachers' performance is critical to students' education and learning outcomes. Therefore, teachers ought to be degree-holding professionals with the ability to learn and teach.

\section{Part 2}

\section{The Era Of Science Education, "Making Science Education Great Again"}

The American Milieu in 1961, when President Kennedy spoke passionately and confidently about the importance of sending a man to the moon had one of the most profound impacts on the revitalization of American science education in our history. After the Russians launched Sputnik into space, competing against the Russians became a national fixation. The government provided billions in promoting, constructing, and subsidizing innovative science education. They commissioned and awarded billion-dollar grants to develop leading-edge textbooks and curricula. According to Alvin Powell of the Harvard News Office "The postSputnik reforms were put in the hands of scientists, much to the dismay of some educators and concerned citizens who previously had enormous input on curriculum design. Several of the changes, such as including hands-on laboratory experience, remain in use today". (Powell, 2007)

Americans students of that generation eventually invented the artificial heart, sophisticated microchips, and high-speed internet. However, after accomplishing those monumental advancements, we've allowed other countries to surpass our zeal for science education and advancement. As a result, American science curriculum and education have drastically shifted towards complacency. According to Alvin Powell of the Harvard News Office, "curriculum reform may be easier to pass in legislation than to realize in the classroom. Teaching science is challenging, requiring debunking common misconceptions and conceptual progressions that require skilled teachers and which take students from a base knowledge to the understanding of higher concepts" (Powell \& Powell, 2007).

\section{Curriculum Reform Recommendation}

The need for curriculum reform is apparent and indisputable. This document contains a summary of three key areas of reform including:

- Inquiry-based learning,

- The social significance of science,

- Improving curriculum map synchronization and updating standards

According to Rodger W. Bybee of The National Academy of Science, "This level of support for curriculum reform is unprecedented in the history of American education. By the 
early 1990s, more than 300 reports admonished those within the educational system to reform science education. The recommendations for education programs emphasized issues, such as updated scientific and technologic knowledge, application of contemporary learning theory and teaching strategies" (Bybee \& McInerne, 1995). There is a consensus amongst science teachers that students' study too many areas, without enough depth in each. For example, the curricula in the middle school contain too many disconnected themes. In addition, each topic is given equal priority; this discourages the in-depth study of foundational topics. It's recommended a revised curriculum that emphasizes a more practical set of foundational themes and concepts are needed.

\section{Incorporating Inquiry Teaching In Science Curriculum}

Student-led inquiry experiences must be the backbone of the curriculum reform. Inquiry teaching develops a better understanding and awareness of science by "actively doing" as opposed to reading about science. According to Bari Walsh and Iman Rastegari of Harvard School of Education "inquiry-education leads to inquiry thinking and processing Routines like See, Think, Wonder might seem almost too simple, but they were designed that way, to be easy to remember and use. The intention is not to simplify ideas; it's to simplify the ways to approach and engage with ideas and make a habit of that process" (Rastegari \& Walsh, 2018).

To improve the middle school science curriculum, we must deviate from traditional models and focus on creating curriculums that motivate and rewards students who think scientifically rather than "memorization". Understanding how children learn and construct their own knowledge about the practicality of science is imperative to promoting science literacy. When curriculums lead with inquiry learning experiences, science is more easily integrated into other subjects. More inquiry and problem-solving demonstrative skills are needed in the classroom. Demonstrative skills through inquiry-based laboratories e.g. experiments and labs have been proven to be the most effective form of instruction for middle and high school students. The bulk of science reform must center on incorporating more inquiry and problem-solving abilities into the curriculum.

\section{Incorporating Social Benefits In Science Curriculum}

Currently, middle and high school science curriculums do not cultivate an atmosphere of creating scientists, and that's a problem. Creating citizens who appreciate science enables them to contribute intelligently to our planet and economy. Science curriculums should incorporate a clear promotion of our shared social responsibility. The translation of scientific inquiry from books to our everyday life must be evident in curriculum development and implementation. Curriculums should better incorporate minorities and notable individuals who've contributed to science, math, medicine, and technology.

Seventy percent of scientists report their interest in science started before middle school. The need to focus on adding science in early childhood curriculum is essential. Starting young learners on a path towards science proficiency and interest is the most efficient and responsive way to reform science education.

Since early childhood educators do not need high-level expertise in complex science, incorporating foundational science curricula at this level is feasible. We need more scientists in the teaching field. Science curriculum reform should incorporate an understanding of the societal benefits of scientific reasoning and processing. This can be achieved through problem solving-centered themes, discussion, and assignments centered on current events. Solving multi-disciplinary problems, which are relevant in nature, is recommended. 


\section{Addressing Global Issues in Science Curriculum}

We live on the same planet earth. Deterioration the condition on one part of the world is going to affect rest of the rest. Therefore everyone needs to collaboratively work to save mother and use resources wisely. And it is important to educate our students the concept of sustainable development. Science curriculum must include global collaboration to tackle the challenges like global warming, weather change and many other issues. A simple attempt in the chemistry class could be neutralizing the chemical waste before disposal. The curriculum must mandate the global project in which students from different parts of the world can work on a same problem. As stated on Asia.org, "the GLOBE project from NASA is a worldwide hands-on science and education program that allows students to work with scientists and other students around the world" (n.d.). With the help of this kind of effort the students may share the local resources with another international group. For example, students living in Earthquake prone zone can share their experience with other students on the different part of the globe.

\section{Science Curriculum Recommendation}

Support for science curriculum reform is unparalleled. Educators have regularly advocated for an update in how American educators teach science. Such updates include how students understand scientific processes, the application of current learning theory, and an entire restructuring of the science curriculum. The reform of science curriculum is based on the overarching goal of scientific literacy in the 21 st century. Scientific literacy should place STEM as an essential and integral part of secondary education in every subject. Surprisingly, teachers are advocating teaching fewer topics and drive more in-depth into foundational contents.

Recommendations for curriculum reform include softening traditional approaches to science education. In practice, the emphasis should be placed on the use of conceptual themes. The volume of topics students are expected to learn should decrease. Another curriculum recommendation is the interconnectivity of various sciences. For example, why and how the nature of science, mathematics, and technology are interrelated to other academic subjects need deeper and clearer emphases in curriculums. For example, according to By John Ceschini of Edweek.org "Neither the arts nor the sciences have a monopoly on teaching creativity, collaboration, or problem-solving skills. Students learn common skills that can be applied between all STEM and arts content areas" (Ceschini, 2019).

\section{Conclusion}

The US is falling behind in science education largely because of stagnating curriculum updates. According to Marc Tucker, president of the National Center on Education and the Economy, the United States cannot long operate a world-class economy if our workers are, as the OECD statistics show, among the worst-educated in the world." (Heim, 2016). Compared to the curriculum in the People's Republic of China, American middle school science curricula have notable deficiencies in the scope, coordination, and arrangement of the curriculum.

The traditional American system of layered-cake approach where students learn one year of earth space, followed by chemistry, physics, and so on is the exact opposite of what every leading country does. Restructuring science teaching primarily at the secondary school level is necessary. Though opening middle science curriculum to inclusivity and discouraging carefully sequenced instruction seems counter-initiative, it appears to be the secret of the most advanced countries. 


\section{References}

About Project. (2016). (n.d.). Retrieved from https://www.aaas.org/programs/project2061/about

Bybee, R. W., \& McInerne, J. (1995). Science Curriculum Reform in the United States. Retrieved May 20, 2019, from http://www.nas.edu/rise/backg3a.htm

Ceschini, J. (2019, February 21). STEM Art: A Brilliant Combination. Retrieved May 20, 2019, from https://www.edweek.org/ew/articles/2014/12/03/13ceschini.h34.html

Heim, J. (2016). On the world stage, U.S. students fall behind. Retrieved May 20, 2019, from https://www.washingtonpost.com/local/education/on-the-world-stage-us-students-fallbehind/2016/12/05/610e1e10-b740-11e6-a677b608fbb3aaf6_story.html?noredirect=on\&utm_term=.1435d5e0f8a7

Powell, A., \& Powell, A. (2007). How Sputnik changed U.S. education. Retrieved May 20, 2019, from https://news.harvard.edu/gazette/story/2007/10/how-sputnik-changed-u-seducation/

Rastegari, I., \& Walsh, B. (2018). Think Better. Retrieved May 20, 2019, from https://www.gse.harvard.edu/news/uk/18/02/think-better

Three Steps to Put Global Issues into Your Science Class. (n.d.). Retrieved from https://asiasociety.org/three-steps-put-global-issues-your-science-class 